\title{
Desenvolvimento vegetativo de plantas de café arábica enxertadas sobre café robusta e submetidas à reposição hídrica
}

\author{
Wezer Lismar Miranda( ${ }^{(1)}$, Rubens José Guimarães ${ }^{(1)}$, Pedro Bueno Magalhães ${ }^{(1)}$, \\ Alberto Colombo ${ }^{(1)}$ e Polyanna Mara de Oliveira(2)
}

\begin{abstract}
(1)Universidade Federal de Lavras, Departamento de Agricultura, Caixa Postal 3.037, CEP 37200-000 Lavras, MG. E-mail: wmlismar@yahoo.com. br, rubensjg@dag.ufla.br, pedroo_bueno@hotmail.com, acolombo@ufla.br ${ }^{(2)}$ Empresa de Pesquisa Agropecuária de Minas Gerais, Unidade Regional Norte de Minas, Rodovia MGT 122, Km 155, Zona Rural, CEP 39527-000 Nova Porteirinha, MG. E-mail: polyanna.mara@epamig.br
\end{abstract}

Resumo - O objetivo deste trabalho foi avaliar o crescimento de plantas de café arábica (Coffea arabica) enxertadas sobre café robusta (C. canephora), submetidas a diferentes níveis de reposição de água. O experimento foi realizado em Lavras, MG, em delineamento experimental de blocos ao acaso, em arranjo fatorial $2 \times 2 \times 5$, com quatro repetições. Foram feitas avaliações em: duas cultivares de C. arabica - Catuaí IAC-99 e Topázio MG-1190 -, dois tipos de plantas - pé-franco e enxertadas sobre C. canephora 'Apoatã IAC-2258' - e cinco níveis de reposição de água - testemunha sem irrigação e quatro coeficientes de cultura, nos valores $0,2,0,3,0,4$ e 0,5 , do plantio até 24 meses, e 0,4, 0,6, 0,8 e 1,0, de 24 a 29 meses -. Utilizou-se turno de rega fixo, com irrigações às terças e às sextas-feiras. Foram avaliados: altura de plantas, diâmetro de copa e diâmetro de caule. Cafeeiros enxertados têm menor crescimento em comparação aos de pé-franco, no período de implantação da lavoura. A substituição do sistema radicular de C. arabica por C. canephora não altera a resposta das plantas à irrigação.

Termos para indexação: Coffea arabica, Coffea canephora, deficiência hídrica, economia de água, enxertia, irrigação.

\section{Vegetative development of arabica coffee plants grafted onto robusta coffee, subjected to water replacement}

\begin{abstract}
Theobjective of this work was toevaluate the vegetative growth ofArabica coffee(Coffea arabica) plants grafted onto robusta coffee (C. canephora), subjected to different levels of water replacement. The experiment was carried out in Lavras, MG, Brazil, in a complete randomized block design, with a $2 \times 2 \times 5$ factorial arrangement and four replicates. Evaluations were done for: two cultivars of C. arabica - Catuaí IAC-99 and Topázio MG-1190 -, two types of plants - ungrafted and grafted onto C. canephora 'Apoatã IAC-2258' -, and five levels of water replacement - the control without irrigation, and four crop coefficients with values of $0.2,0.3,0.4$, and 0.5 from planting to 24 months, and of $0.4,0.6,0.8$, and 1.0 from 24 to 29 months -. A fixed watering shift was used, with irrigations on Tuesdays and on Fridays. Plant height, and crown and stem diameters were evaluated. Grafted trees have lower growth compared to the ungrafted ones, during the establishment of the crop. The replacement of the root system of C. arabica by C. canephora does not alter the response of plants to irrigation.
\end{abstract}

Index terms: Coffea arabica, Coffea canephora, water deficit, water economy, grafting, irrigation.

\section{Introdução}

Aenxertia é uma técnica bastante difundida na cultura do cafeeiro, como forma de viabilizar seu cultivo em áreas que apresentam limitações bióticas ou abióticas ao bom desenvolvimento do sistema radicular.

A maioria das pesquisas tem priorizado o uso de Coffea canephora Pierre ex A. Froehner como porta-enxerto, pela maior tolerância a nematoides, em comparação a cultivares de C. arabica L. (Dias et al., 2009). A enxertia visa o aproveitamento do sistema radicular mais desenvolvido de C. canephora para obtenção de alta produtividade, elevado vigor das plantas, maior tamanho de frutos, melhor qualidade de bebida e adaptação das plantas a áreas com baixa precipitação, com C. arabica usada como enxerto (Tomaz et al., 2005).

Fahl et al. (1998) constataram que a enxertia também é útil em áreas isentas de nematoides, por promover melhor desenvolvimento em altura e diâmetro de copa e propiciar maior teor de potássio nas copas, o que indica maior eficiência na absorção de nutrientes da solução do solo, em comparação a plantas não enxertadas. No entanto, resultados diferentes também têm sido

Pesq. agropec. bras., Brasília, v.46, n.12, p.1618-1624, dez. 2011 
observados, com maior diâmetro de caule, altura de plantas, área foliar e massa de matéria seca em plantas pé-franco (Oliveira et al., 2004; Dias, 2006; Ferreira, 2008). Portanto, há a necessidade de mais pesquisas, em diferentes situações e com uso de outras metodologias, para melhor elucidar os efeitos dessa tecnologia no desenvolvimento e no desempenho da cultura do cafeeiro.

A irrigação é outra tecnologia que vem sendo amplamente aplicada à cafeicultura. Contudo, mais informações ainda são necessárias quanto ao melhor manejo de épocas de irrigação e de lâminas d'água, e ao momento certo para irrigar o cafeeiro, para uniformização da florada e redução da bienalidade de produção (Silva et al., 2008; Rezende et al., 2009).

Vilella \& Faria (2003) observaram incremento significativo em altura da planta, diâmetro do caule, diâmetro da copa, número de internódios e comprimento dos ramos primários, além de incremento na produtividade, com a aplicação de $100 \%$ da lâmina, calculada a partir de evaporação do tanque classe A. Nazareno et al. (2003), Carvalho et al. (2006) e Gomes et al. (2007) também relataram acréscimo nesses parâmetros, em cafeeiros irrigados com lâminas crescentes de reposição de água.

O objetivo deste trabalho foi avaliar o crescimento de plantas de C. arabica enxertadas sobre $C$. canephora, submetidas a diferentes níveis de reposição de água.

\section{Material e Métodos}

O experimento foi realizado no Setor de Cafeicultura, do Departamento de Agricultura, da Universidade Federal de Lavras (Ufla), Lavras, $\mathrm{MG}\left(21^{\circ} 14^{\prime} \mathrm{S}, 45^{\circ} 00^{\prime} \mathrm{W}\right.$, a $918,8 \mathrm{~m}$ de altitude). O clima, conforme Dantas et al. (2007), é do tipo Cwa da classificação de Koeppen, com inverno seco e chuvas predominantes no verão, com precipitação média anual de $1.530 \mathrm{~mm}$. A temperatura média anual é de $19,4^{\circ} \mathrm{C}$. O solo da área experimental é classificado como Latossolo Vermelho distroférrico (Santos et al., 2006).

Utilizou-se o delineamento experimental de blocos ao acaso, em arranjo fatorial $2 \times 2 \times 5$ - duas cultivares de C. arabica, dois tipos de plantas (pé-franco e enxertadas) e cinco níveis de reposição de água - com parcelas subdivididas no tempo, quatro repetições e oito plantas por parcela, das quais seis consideradas úteis.

As mudas de cultivares de $C$. arabica Catuaí IAC-99 e Topázio MG-1190, tanto as de pé-franco quanto as enxertadas sobre $C$. canephora Apoatã IAC-2258, foram formadas no Setor de Cafeicultura da Ufla, em junho de 2006 a março de 2007. O plantio em campo foi realizado em março de 2007, em espaçamento de 3,5x0,8 m.

A adubação foi realizada com base nos resultados da análise de fertilidade do solo e atendeu às recomendações da Comissão de Fertilidade do Solo do Estado de Minas Gerais (Guimarães et al., 1999). As adubações de manutenção foram feitas via fertirrigação, nos tratamentos irrigados, e manualmente nas testemunhas sem irrigação e nas bordaduras. Os adubos utilizados foram: ureia pecuária, cloreto de potássio e MAP. As adubações foram parceladas em quatro vezes, entre novembro e fevereiro.

Foram avaliados cinco níveis de reposição de água: testemunha sem irrigação e quatro lâminas calculadas a partir de quatro coeficientes de cultura $(\mathrm{Kc})$. Os valores de $\mathrm{Kc}$ adotados, do plantio até março de 2009, foram: 0,2, 0,3, 0,4 e 0,5. Em março de 2009, esses valores foram alterados para $0,4,0,6,0,8$ e 1,0 , em razão do desenvolvimento da lavoura em altura, diâmetro de copa e índice de área foliar (IAF), bem como da alteração na reflectância da radiação solar por solo e plantas, na resistência das plantas à transferência de vapor d'água para a atmosfera e na evaporação direta de água do solo sem cobertura vegetal. A adoção desses valores de Kc se baseou nos estudos realizados por Favarin et al. (2002), para estimativa do IAF, e no método de estimativa de Kc para cafeeiro proposto por Villa Nova et al. (2002). A aplicação dos tratamentos teve início em setembro de 2007, com uso dos diferentes níveis de irrigação.

De janeiro de 2008 a março de 2009, foram realizadas sete avaliações (8/1, 19/3, 27/5, $30 / 7,8 / 10,10 / 12$ e 4/2), nos tratamentos com o primeiro conjunto de $\mathrm{Kc}$; e de março a agosto de 2009 (8/4, 22/6 e 14/8) três avaliações, com o segundo conjunto de Kc. Foram avaliadas as 
seguintes características: altura de plantas $(\mathrm{cm})$, medida da superfície do solo até o meristema apical; diâmetro de caule $(\mathrm{mm})$, determinado com auxílio de paquímetro a $10 \mathrm{~cm}$ do solo; e diâmetro de copa $(\mathrm{cm})$, medido transversalmente à linha de plantio, tendo-se considerado as extremidades dos ramos plagiotrópicos.

Para a avaliação do crescimento das plantas, os dados foram analisados de forma separada, nos dois períodos avaliados, em virtude da alteração do coeficiente de cultura $(\mathrm{Kc})$.

Para o cálculo da evapotranspiração de referência (ETo), foi utilizado o programa Irriga, que processa dados diários, conforme o método de Penman-Monteith-FAO. A evapotranspiração da cultura (ETc), para cada tratamento, foi definida pela multiplicação da ETo pelo respectivo valor de Kc. O sistema de irrigação utilizado foi o de gotejamento, com linhas laterais de polietileno e emissores autocompensantes com vazão nominal de $3,78 \mathrm{~L}$ por hora (para pressões de

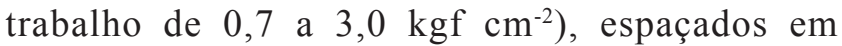
$0,4 \mathrm{~m}$. As irrigações foram feitas com turno de rega fixo às terças e sextas-feiras. As lâminas aplicadas foram determinadas pelo balanço entre a evapotranspiração da cultura (ETc) e as precipitações ocorridas no intervalo entre as duas irrigações (Tabela 1). Os dados meteorológicos, necessários para o cálculo da irrigação, foram obtidos a partir de estação meteorológica automática instalada na área experimental.

Os dados foram submetidos à análise de variância, e as médias foram comparadas pelo teste de Scott-Knott, a 5\% de probabilidade. As análises estatísticas foram realizadas com o Sisvar (Ferreira, 2008).

\section{Resultados e Discussão}

Pelas lâminas de irrigação aplicadas (Tabela 1), observou-se que, mesmo com o uso de valores de Kc abaixo dos recomendados - de 0,9 a 1,10 (Allen et al., 1998) -, as precipitações não foram suficientes para suprir a demanda hídrica da cultura.

Houve efeito significativo quanto ao tipo de planta (enxertada ou não), quanto à cultivar (Catuaí IAC-99 ou Topázio MG-1190) e com relação às diferentes lâminas de irrigação aplicadas, mas não para as interações entre os fatores (Tabela 2).

Com relação ao tipo de muda, as de pé-franco apresentaram maior média de altura, com crescimento $18,34 \%$ superior ao das enxertadas (Tabela 3). Esse comportamento mantevese mesmo com a alteração do valor do Kc, nas mudas de 24 a 29 meses. As mudas em pé-franco, avaliadas após a mudança, apresentaram altura média $12,45 \%$ superior à das enxertadas, o que representa diferença de cerca de $12,29 \mathrm{~cm}$. Esse resultado pode ser explicado pelo estresse causado pela enxertia, na fase inicial da lavoura em campo. No entanto, Fahl et al. (1998) não observaram menor crescimento de plantas em pé-franco, em área isenta de nematoide, e sim maior altura das plantas enxertadas. Cabe ressaltar que esses autores trabalharam com cafeeiros adultos e não com plantas na fase inicial de desenvolvimento, o que pode ter diluído no tempo os efeitos do estresse inicial da enxertia. Ferreira (2008) e Tomaz et al. (2005) não encontraram diferença significativa quanto ao crescimento da parte aérea entre plantas pé-franco e enxertadas. Os resultados obtidos no presente trabalho corroboram os de Oliveira et al. (2004) e Dias et al. (2008).

As mudas em pé-franco apresentaram $27,69 \%$ de diâmetro de copa e $23,60 \%$ de caule, superiores aos das mudas enxertadas do plantio até 24 meses. No período seguinte (24 a 29 meses), esse comportamento manteve-se com maiores médias nas plantas em pé-franco com valores 22,04\% superiores, para o diâmetro de copas, e 16,82\% superiores para o de caules. O resultado obtido para essas características é indicativo de que o prejuízo causado pela enxertia ao desenvolvimento das plantas manteve-se até o final do experimento, aos

Tabela 1. Lâminas de irrigação (mm) acumuladas anualmente para cada tratamento, de acordo com os coeficientes de cultura $(\mathrm{Kc})$ utilizados.

\begin{tabular}{lcccc}
\hline Ano & \multicolumn{4}{c}{ Kc } \\
\cline { 2 - 5 } & 0,5 & 0,4 & 0,3 & 0,2 \\
\hline 2007 & 102,72 & 82,18 & 61,63 & 41,09 \\
2008 & 288,21 & 230,56 & 172,92 & 115,28 \\
2009 & 384,12 & 307,30 & 230,47 & 153,65 \\
\hline
\end{tabular}


29 meses pós-plantio. De acordo com Dias (2006), uma possível incompatibilidade entre enxerto e porta-enxerto pode ser outra causa para o menor crescimento das plantas enxertadas.

Quanto às cultivares, não houve diferença significativa em relação à altura e ao diâmetro de caule; porém, observou-se que o diâmetro de copa da cultivar Catuaí IAC-99, no primeiro período avaliado, foi 8,09\% superior (Tabela 4). Essa superioridade foi mantida no período seguinte, com diâmetro de copa da cultivar Catuaí IAC-99 7,60\% superior ao da Topázio MG-1190.

Tabela 2. Resumo da análise de variância quanto à altura, diâmetro de copa e de caule de plantas de café arábica, de acordo com a cultivar, o tipo de planta (enxertada ou pé franco) e as lâminas de reposição de água, nos períodos do plantio até 24 meses e de 24 a 29 meses pós-plantio.

\begin{tabular}{|c|c|c|c|c|}
\hline \multirow[t]{2}{*}{ Fonte de variação } & \multirow[t]{2}{*}{ GL } & \multicolumn{3}{|c|}{ Quadrado médio } \\
\hline & & Altura de planta & Diâmetro de copa & Diâmetro de caule \\
\hline & & \multicolumn{3}{|c|}{ Do plantio até 24 meses } \\
\hline Bloco & 3 & 398,258 & 788,029 & 0,934 \\
\hline Cultivar & 1 & 812,387 & $4.102,675^{*}$ & 0,110 \\
\hline Tipo de planta & 1 & $14.842,198 * *$ & $40.056,242 * *$ & $20,593 * *$ \\
\hline Nível de reposição & 4 & $1.739,435^{*}$ & $1.881,697$ & $2,248 * *$ \\
\hline Cultivar x tipo de planta & 1 & 618,891 & $2.142,172$ & $2,158 *$ \\
\hline Cultivar x nível de reposição & 4 & 365,203 & $1.408,637$ & 0,536 \\
\hline Enxerto x nível de reposição & 4 & 221,564 & 572,222 & 0,210 \\
\hline Cultivar $\mathrm{x}$ tipo de planta $\mathrm{x}$ nível de reposição & 4 & 208,868 & 649,909 & 0,357 \\
\hline Erro 1 & 12 & 346,271 & 670,445 & 0,411 \\
\hline Época de avaliação & 6 & $24.034,314 * *$ & $31.618,280 * *$ & $32,346^{* *}$ \\
\hline Época de avaliação x cultivar & 6 & 12,265 & 97,757 & 0,017 \\
\hline Época de avaliação x tipo de planta & 6 & 84,579 & 402,641 & 0,689 \\
\hline Época de avaliação x nível de reposição & 24 & 37,134 & 72,753 & 0,089 \\
\hline Época de avaliação x cultivar x tipo de planta & 6 & 33,628 & 53,092 & 0,032 \\
\hline Época de avaliação x cultivar x nível de reposição & 24 & 12,608 & 33,133 & 0,023 \\
\hline Época de avaliação x tipo de planta x nível de reposição & 24 & 9,087 & 23,530 & 0,016 \\
\hline Época de avaliação x cultivar x tipo de planta x nível de reposição & 24 & 14,504 & 34,832 & 0,025 \\
\hline Erro 2 & 405 & 40,230 & 92,804 & 0,054 \\
\hline$\overline{\mathrm{CV}(\%)}$ & - & 30,36 & 37,24 & 35,58 \\
\hline \multirow[t]{2}{*}{ Média geral } & - & 61,298 & 69,53 & 1,80 \\
\hline & & \multicolumn{3}{|c|}{ De 24 a 29 meses } \\
\hline Bloco & 3 & 374,634 & 667,587 & 0,342 \\
\hline Cultivar & 1 & 206,906 & $4.507,793 *$ & 0,096 \\
\hline Tipo de planta & 1 & $9.071,251 * *$ & $32.659,433 * *$ & $16,401 * *$ \\
\hline Nível de reposição & 4 & $782,742 *$ & 574,823 & $1,454 *$ \\
\hline Cultivar x tipo de planta & 1 & 159,381 & 152,753 & 0,004 \\
\hline Cultivar x nível de reposição & 4 & 156,021 & 771,933 & 0,397 \\
\hline Enxerto x nível de reposição & 4 & 231,118 & 432,347 & 0,267 \\
\hline Cultivar $\mathrm{x}$ tipo de planta $\mathrm{x}$ nível de reposição & 4 & 42,010 & 222,688 & 0,171 \\
\hline Erro 1 & 12 & 204,944 & 507,830 & 0,273 \\
\hline Época de avaliação & 2 & $1.721,025 * *$ & $875,810^{* *}$ & $4,227 * *$ \\
\hline Época de avaliação x cultivar & 2 & 0,445 & 26,771 & 0,013 \\
\hline Época de avaliação x tipo de planta & 2 & 35,443 & 42,395 & 0,001 \\
\hline Época de avaliação x nível de reposição & 8 & 5,441 & 32,564 & 0,015 \\
\hline Época de avaliação x cultivar x tipo de planta & 2 & 1,832 & 16,867 & 0,060 \\
\hline Época de avaliação x cultivar x nível de reposição & 8 & 17,794 & 7,616 & 0,017 \\
\hline Época de avaliação x tipo de planta x nível de reposição & 8 & 12,350 & 69,199 & 0,011 \\
\hline Época de avaliação x cultivar x tipo de planta x nível de reposição & 8 & 13,767 & 62,355 & 0,009 \\
\hline Erro 2 & 165 & 67,901 & 117,019 & 0,062 \\
\hline $\mathrm{CV}(\%)$ & - & 13,66 & 19,18 & 15,62 \\
\hline Média geral & - & 104,80 & 117,52 & 3,35 \\
\hline
\end{tabular}

** e *Significativo pelo teste $\mathrm{F}$, a 1 e $5 \%$ de probabilidade, respectivamente. 
Observou-se efeito linear significativo das lâminas de reposição de água sobre as médias de altura e de diâmetros de copas e de caules, em ambos os períodos de avaliação (Figura 1). Como não houve efeito da interação entre os fatores, esse efeito linear foi independente da cultivar ou do tipo de planta utilizado. Assim, a hipótese de que mudas enxertadas pudessem ter comportamento diferente das de pé-franco, sob diferentes lâminas de reposição, não se confirmou.

O comportamento linear em ambos os períodos de avaliação (Figura 1) evidencia que o nível ótimo de reposição de água provavelmente está acima dos 50\% da ETo $(\mathrm{Kc}=0,5)$, estabelecidos como limite superior para plantas no período inicial de desenvolvimento no campo, e dos $100 \%$ da ETo para plantas no período de 24 a 29 meses. Além disso, os maiores coeficientes

Tabela 3. Altura, diâmetros de copa e de caule de plantas de café arábica, enxertadas ou não sobre café robusta, nos períodos do plantio até 24 meses e de 24 a 29 meses pósplantio $^{(1)}$.

\begin{tabular}{lccc} 
Cultivar & $\begin{array}{c}\text { Altura de planta } \\
\text { - }\end{array}$ & $\begin{array}{c}\text { Diâmetro de copa } \\
\text { Diâmetro de caule }\end{array}$ \\
\hline Enxertadas & $0,6645 \mathrm{a}$ & $0,7798 \mathrm{a}$ & $0,0199 \mathrm{a}$ \\
Pé-franco & $0,5615 \mathrm{~b}$ & $0,6107 \mathrm{~b}$ & $0,0161 \mathrm{~b}$ \\
\hline \multicolumn{4}{c}{24 aos 29 meses } \\
Enxertadas & $1,1095 \mathrm{a}$ & $1,2918 \mathrm{a}$ & $0,0361 \mathrm{a}$ \\
Pé-franco & $0,9866 \mathrm{~b}$ & $1,0585 \mathrm{~b}$ & $0,0309 \mathrm{~b}$ \\
\hline
\end{tabular}

${ }^{(1)}$ Médias seguidas de letras iguais não diferem entre si pelo teste de ScottKnott, a 5\% de probabilidade.

Tabela 4. Altura, diâmetros de copa e de caule de plantas de café arábica, cultivares Catuaí IAC 99 e Topázio MG 1190, nos períodos do plantio até 24 meses e de 24 a 29 meses pós-plantio ${ }^{(1)}$.

\begin{tabular}{lccc}
\hline Cultivar & $\begin{array}{c}\text { Altura } \\
\text { de planta }\end{array}$ & $\begin{array}{c}\text { Diâmetro } \\
\text { de copa }\end{array}$ & $\begin{array}{c}\text { Diâmetro } \\
\text { de caule }\end{array}$ \\
\hline & -3 & Plantio até 24 meses \\
Catuaí IAC 99 & $0,6250 \mathrm{a}$ & $0,7223 \mathrm{a}$ & $0,0182 \mathrm{a}$ \\
Topázio MG 1190 & $0,6009 \mathrm{a}$ & $0,6682 \mathrm{~b}$ & $0,0179 \mathrm{a}$ \\
\hline \multicolumn{4}{c}{ 24 a 29 meses } \\
Catuaí IAC 99 & $1,0573 \mathrm{a}$ & $1,2185 \mathrm{a}$ & $0,0337 \mathrm{a}$ \\
Topázio MG 1190 & $1,0388 \mathrm{a}$ & $1,1318 \mathrm{~b}$ & $0,0333 \mathrm{a}$ \\
\hline
\end{tabular}

${ }^{(1)}$ Médias seguidas de letras iguais não diferem entre si pelo teste de ScottKnott, a 5\% de probabilidade. lineares no primeiro período de avaliação indicam maior sensibilidade de resposta das características avaliadas à irrigação, nesse período; o que já era esperado.

No primeiro período de avaliação, a testemunha sem irrigação apresentou altura estimada de 55,98 cm e, quando a lâmina de $50 \%$ da ETo foi aplicada, a altura das plantas passou a 65,47 cm (Figura 1), o que representa aumento significativo de $16,95 \%$ no crescimento em altura das plantas. No período de 24 a 29 meses, a testemunha apresentou altura estimada de $99,54 \mathrm{~cm}$ e, com a aplicação da lâmina de $100 \%$ da ETo, a altura das plantas passou a $108,95 \mathrm{~cm}$, ou seja, houve superioridade de $9,45 \%$ no crescimento em altura das plantas.

Vilella \& Faria (2003) e Carvalho et al. (2006) também observaram aumento linear da altura de plantas em consequência do aumento da lâmina de irrigação.

No primeiro período de avaliação, a testemunha apresentou diâmetro de copa estimado de $63,68 \mathrm{~cm}$ e, quando se aplicou a lâmina de $50 \%$ da ETo, o diâmetro das plantas passou a 74,12 cm (Figura 1), ou seja, houve superioridade de $16,39 \%$ no crescimento do diâmetro de copas pelo aumento na disponibilidade de água. No segundo período, a testemunha apresentou diâmetro de copa estimado de $112,74 \mathrm{~cm}$ e, com a aplicação da lâmina de $100 \%$ da ETo, o diâmetro das plantas passou a $121,27 \mathrm{~cm}$, ou seja, houve superioridade de 7,56\%.

Quanto ao diâmetro de copas, Nazareno et al. (2003) e Vilella \& Faria (2003) também obtiveram equação linear quanto ao efeito de lâminas de irrigação.

No período do plantio até 24 meses, a testemunha apresentou diâmetro de caule estimado de $1,61 \mathrm{~cm} \mathrm{e,}$ quando se aplicou a lâmina de $50 \%$ da ETo, o diâmetro de caule das plantas passou a 1,96 cm (Figura 1), ou seja, houve superioridade de $21,74 \%$. No período de 24 a 29 meses após o plantio, a testemunha apresentou diâmetro de caule estimado de $3,12 \mathrm{~cm}$ e, com a aplicação da lâmina de $100 \%$ da ETo, o diâmetro de caule das plantas passou a $3,53 \mathrm{~cm}$, ou seja, foi portanto $13,14 \%$ superior.

Os resultados obtidos estão de acordo com Gomes et al. (2007), que relataram maior diâmetro de caule, quanto ao tratamento que recebeu maior lâmina de irrigação e menor diâmetro nas plantas não irrigadas. 

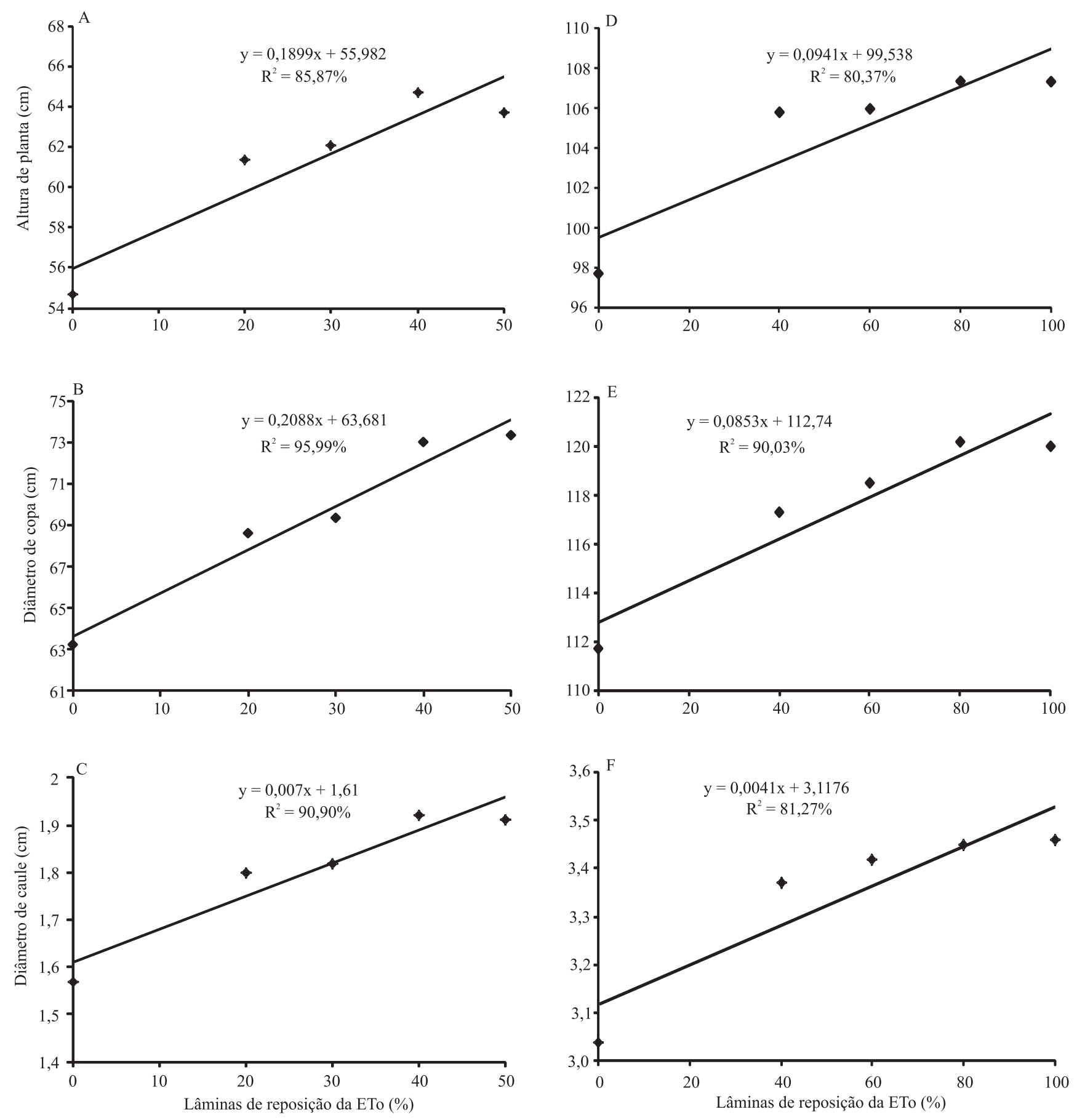

Médias Observadas

Figura 1. Altura, diâmetros de copa e de caule de plantas de café arábica, submetidas a diferentes lâminas de reposição de água, do plantio até 24 meses (A a C) e de 24 a 29 meses pós-plantio (D a F).

\section{Conclusões}

1. Plantas de Coffea arabica enxertadas sobre C. canephora têm menor crescimento em comparação às de pé-franco, no período de implantação da lavoura.
2. O estresse causado pela enxertia anula os possíveis efeitos benéficos que a substituição do sistema radicular de $C$. arabica por $C$. canephora possa ter sobre a resposta das plantas à disponibilidade hídrica. 
3. As mudas enxertadas respondem ao aumento na disponibilidade hídrica da mesma forma que as mudas em pé-franco.

\section{Agradecimento}

Ao Consórcio Brasileiro de Pesquisa e Desenvolvimento do Café, pelo apoio financeiro.

\section{Referências}

ALLEN, R.G.; PEREIRA, L.S.; RAES, D.; SMITH, M. Crop evapotranspiration: guidelines for computing crop water requirements. Rome: Food and Agriculture Organization of the United Nations, 1998. 300p. (FAO. Irrigation and drainage paper, 56).

CARVALHO, C.H.M. de; COLOMBO, A.; SCALCO, M.S.; MORAIS, A.R. de. Evolução do crescimento do cafeeiro (Coffea arabica L.) irrigado e não irrigado em duas densidades de plantio. Ciência e Agrotecnologia, v.30, p.243-250, 2006.

DANTAS, A.A.A.; CARVALHO, L.G. de; FERREIRA, E. Classificação e tendências climáticas em Lavras, MG. Ciência e Agrotecnologia, v.31, p.1862-1866, 2007.

DIAS, F.P. Crescimento vegetativo e anatomia caulinar de cafeeiros enxertados. 2006. 99p. Tese (Doutorado) - Universidade Federal de Lavras, Lavras.

DIAS, F.P.; CASTRO, D.M. de; MENDES, A.N.G.; VALLONE, H.S.; CARVAlHO, A.M. de; CARVALHO, G.R. Estudo anatômico de cafeeiros enxertados. Ciência e Agrotecnologia, v.33, p.735-742, 2009.

DIAS, F.P.; MENDES, A.N.G.; VALLONE, H.S.; CARVALHO, A.M. de; CARVALHO, S.P. de. Desenvolvimento de cafeeiros enxertados Apoatã IAC-2258 cultivados em recipiente de 250 litros. Ciência e Agrotecnologia, v.32, p.385-390, 2008.

FAHL, J.I.; CARELLI, M.L.C.; GALLO, P.B.; COSTA, W.M. da; NOVO, M. do C. de S.S. Enxertia de Coffea arabica sobre progênies de $C$. canephora e de $C$. congensis no crescimento, nutrição mineral e produção. Bragantia, v.57, p.297-312, 1998.

FAVARIN, J.L.; DOURADO-NETO, D.; GARCÍA, A.G.; VILLA NOVA, N.A.; FAVARIN, M.G.G.V. Equações para a estimativa do índice de área foliar do cafeeiro. Pesquisa Agropecuária Brasileira, v.37, p.769-773, 2002.

FERREIRA, A.D. Eficiência do porta-enxerto Apoatã IAC-2258 (Coffea canephora) na nutrição mineral e no desenvolvimento de cafeeiros (Coffea arabica L.). 2008. 102p. Dissertação (Mestrado) - Universidade Federal de Lavras, Lavras.
FERREIRA, D.F. SISVAR: um programa para análises e ensino de estatística. Revista Symposium, v.6, p.36-41, 2008.

GOMES, N.M.; LIMA, L.A.; CUSTÓDIO, A.A. de P. Crescimento vegetativo e produtividade do cafeeiro irrigado no sul do Estado de Minas Gerais. Revista Brasileira de Engenharia Agrícola e Ambiental, v.11, p.564-570, 2007.

GUIMARÃES, P.T.G.; GARCIA, A.W.R.; ALVAREZ VENEGAS, V.H.; PREZOTTI, L.C.; VIANA, A.S.; MIGUEL, A.E.; MALAVOLTA, E.; CORREAA, J.B.; LOPES, A.S.; NOGUEIRA, F.D.; MONTEIRO, A.V.C. Cafeeiro. In: RIBEIRO, A.C.; GUIMARÃES, P.T.G.; ALVAREZ VENEGAS, V.H. (Ed.). Recomendação para o uso de corretivos e fertilizantes em Minas Gerais: 5a aproximação. Viçosa: CFSEMG, 1999. p.289-302.

NAZARENO, R.B.; OLIVEIRA, C.A. da S.; SANZONOWICZ, C.; SAMPAIO, J.B.R.; SILVA, J.C.P. da; GUERRA, A.F. Crescimento inicial do cafeeiro Rubi em resposta a doses de nitrogênio, fósforo e potássio e a regimes hídricos. Pesquisa Agropecuária Brasileira, v.38, p.903-910, 2003.

OLIVEIRA, A.L. de; GUIMARÃES, R.J.; SOUZA, C.A.S.; CARVALHO, J. de A.; MENDES, A.N.G.; GUIMARÃES, R. de S. Desenvolvimento de cafeeiros (Coffea arabica L.) enxertados submetidos a diferentes níveis de reposição de água. Ciência e Agrotecnologia, v.28, p.1291-1298, 2004.

REZENDE, F.C.; FARIA, M.A. de; MIRANDA, W.L. Efeitos do potencial de água da folha na indução da floração e produção do cafeeiro (Coffea arabica L.). Coffee Science, v.4, p.126-135, 2009.

SANTOS, H.G. dos; JACOMINE, P.K.T.; ANJOS, L.H.C. dos; OLIVEIRA, V.A. de; OLIVEIRA, J.B. de; COELHO, M.R.; LUMBRERAS, J.F.; CUNHA, T.J.F. (Ed.). Sistema brasileiro de classificação de solos. 2.ed. Rio de Janeiro: Embrapa Solos, 2006. $306 \mathrm{p}$.

SILVA, C.A. da; TEODORO, R.E.F.; MELO, B. de. Produtividade e rendimento do cafeeiro submetido a lâminas de irrigação. Pesquisa Agropecuária Brasileira, v.43, p.387-394, 2008.

TOMAZ, M.A.; SAKIYAMA, N.S.; MARTINEZ, H.E.P.; CRUZ, C.D.; PEREIRA, A.A.; FREITAS, R.S. de. Porta-enxertos afetando o desenvolvimento de plantas de Coffea arabica L. Ciência Rural, v.35, p.570-575, 2005.

VILELLA, W.M. da C.; FARIA, M.A. de. Crescimento de cafeeiros submetidos a cinco lâminas de irrigação e três parcelamentos de adubação. Revista Irriga, v.8, p.168-177, 2003.

VILLA NOVA, N.A.; FAVARIN, J.L.; ANGELOCCI, L.R.; DOURADO-NETO, D. Estimativa do coeficiente de cultura do cafeeiro em função de variáveis climatológicas e fitotécnicas. Bragantia, v.61, p.81-88, 2002.

Recebido em 26 de maio de 2011 e aprovado em 25 de novembro de 2011 